\title{
LOS BENEFICIOS PARROQUIALES: UN ACERCAMIENTO AL ESTUDIO DEL CLERO SECULAR
}

\author{
POR \\ Silvia María Pérez GonZÁLEZ \\ Universidad Pablo de Olavide (Sevilla)
}

\section{RESUMEN}

Las escribanías públicas sevillanas durante el periodo estudiado (1441-1504) tuvieron entre sus clientes más activos a un número destacado de miembros del clero secular. Ello nos ha permitido descender al nivel del clero de las parroquias para estudiarlo desde el punto de vista del beneficio parroquial gozado. La imagen obtenida del beneficio es la de una propiedad más dentro del patrimonio clerical, susceptible de cualquier negocio.

PALABRAS CLAVES: Clero secular, Parroquia, Economía clerical, Beneficio parroquial, Andalucía, Documentación notarial

\section{THE PARISH BENEFITS: AN APPROXIMATION TO THE STUDY OF THE SECULAR CLERGY}

\section{ABSTRACT}

From 1441 to 1504 , the notary public offices in Seville had a significant number of members of the secular clergy amongst their more active customers. This fact allows us to study the parochial clergy from the point of view of parish benefits. Thus, we can deduce that priests enjoyed this kind of benefits as an important part of their personal assets, and they used them in all kinds of business.

KEY WORDS: Secular priesthood, Parish church, Clerical economy, Parish benefits, Andalusia, Notarial documentation

Recibido/Received 19-05-2010

Aceptado/Accepted 18-01-2012 
Clérigo es una palabra polisémica. Designa a un grupo social con su identidad e incluye muy diferentes categorías dentro de él. ${ }^{1}$ Por eso partimos de una definición previa y general para distinguir al clérigo en sus diferentes clases y grados.

El Sínodo diocesano de Toledo de 1393 usa la definición tradicional. Un clérigo es «in sortem Dei electus» (los elegidos para la heredad de Dios). ${ }^{2}$ El Código de Derecho Canónico ${ }^{3}$ promulgado en 1917 c.108, 1 dice: «Llámanse clérigos los que al menos por la primera tonsura han sido consagrados a los misterios divinos». Esta definición vale también para los clérigos medievales que, en su gran mayoría, no pasaron de simples tonsurados. Todos los clérigos gozaron de los mismos privilegios y de un mismo status jurídico, pero no todos fueron iguales. No lo fueron en razón del orden sacerdotal ${ }^{4}$ recibido ni en razón de la jurisdicción eclesiástica que ostentaban. Las diferencias son mucho mayores desde el punto de vista socioeconómico, intelectual, santidad personal, etc.

Estudiamos el clero secular en la diócesis de Sevilla (1441-1504) desde el punto de vista del beneficio parroquial de que gozaban: beneficiado cural, beneficiado servidero, y prestamero..$^{5}$ Hay una documentación muy rica, que empieza a ser cada vez más utilizada para abordar los temas vinculados a la Historia de la Iglesia: los Protocolos Notariales ${ }^{6}$ en nuestro caso, los asientos custodiados en el Archivo Histórico Provincial de Sevilla. ${ }^{7}$

${ }^{1}$ Cárcel Ortí, M. M. 2005. «El clero secular en Europa en la Baja Edad Media». Anuario de Estudios Medievales 35/2: 971-1050. Nieto Soria J. M. 2004. «El clero secular». Medievalismo: Boletín de la Sociedad Española de Estudios Medievales, 13-14: 95-112. Sánchez Herrero, J. 1978. Las diócesis del Reino de León. Siglos XIV y XV: 143-191. León: Centro de investigación y estudios «San Isidoro». Sánchez Herrero, J. 1997. «El Trabajo del clero en la Edad Media». Acta historica et archeologica medieavalia, 18: 93. Sánchez Herrero, J. 2002. «El clero en tiempos de Isabel I de Castilla», en J. Valdeón Varuque. II Simposio sobre el Reinado de Isabel la Católica: Sociedad y economía en tiempos de Isabel La Católica:151-182. Valladolid: Ámbito

${ }^{2}$ Sánchez Herrero, J. 1976. Concilios provinciales y sínodos toledanos de los siglos XIV y XV. La religiosidad cristiana del clero y pueblo: 177. La Laguna: Universidad de La Laguna

${ }^{3}$ Miguélez Domínguez, L., Alonso Morán, S., Cabreros de Anta, M. 1954. Código de Derecho canónico: 47. Madrid: Editorial Católica

${ }^{4}$ Indicamos su categoría de modo referencial, pues ésta no necesariamente correspondía a las órdenes sagradas recibidas, órdenes que desgraciadamente la documentación silencia, pues el tratamiento jurídico era diferente.

${ }^{5}$ Estamos hablando del clero parroquial sevillano, sin tener en cuenta lo que ocurrió en otras diócesis.

${ }^{6}$ Candau Chacón, M. L. 1998. «Las formas de vida eclesiástica y las fuentes notariales», en En torno a la documentación notarial y a la historia: 111-124. Sevilla: Colegio Notarial. Jacquart, J. 1973. «Sources Notariales et Historie Rurale», en Actas del II Coloquio de Metodología Histórica Aplicada. La Documentación Notarial y la Historia. 239-254. Santiago de Compostela: Universidad de Santiago. Ostos Salcedo, P. y Pardo Rodríguez, M. L. 1995. El notariado andaluz en el tránsito de la Edad Media a la Edad Moderna. Sevilla: Colegio Notarial. Igual Luis, D. 2004. «Las perspectivas de investigación sobre fondos notariales en Castilla», en Aragón en la Edad Media: perspectivas actuales sobre las fuentes notariales de la Edad Media: 127-152. Zaragoza: Universidad de Zaragoza.

${ }_{7}$ Toda la documentación procede del Archivo Histórico Provincial de Sevilla. Sección Protocolos. Indicamos el Legajo (leg.) y el folio (fol.). El periodo analizado comprende los años 1441 a 1504. 
Otros autores han aportado interesantes novedades a este tema, han aplicado una metodología original y han presentado nuevas conclusiones. ${ }^{8}$ Desde los datos obtenidos en el Archivo de Protocolos Notariales de Sevilla sobre un clero, el parroquial, hacemos esta contribución sobre un grupo social del que aún queda mucho por saber. ${ }^{9}$

\section{Una Singularidad de la Diócesis de SeVILla: sus Parroquias}

Un de los puntos más peculiares de la organización de la diócesis de Sevilla, por defecto de suficiente documentación todavía no totalmente claro, son sus parroquias. ${ }^{10}$ La parroquia es la última división territorial de la diócesis. En ella se hallan diferentes tipos de clérigos beneficiados. Uno de ellos, el «cura», responsable de la cura animarum, otro, el beneficiado que gozaba del beneficio cural. Era siempre un presbítero. Los otros clérigos en la parroquia van de simples clérigos a presbíteros, siendo simples beneficiados que gozan de los beneficios simples.

\footnotetext{
${ }^{8}$ Por citar algunos: Aldea, Q. 1973. «La economía de las iglesias locales en la Edad Media y Moderna». Hispania Sacra XXVI: 27-42. Aranda Pérez, F. J. 2000. «El clero parroquial también se acabilda. El cabildo de curas y beneficazos de Toledo», en Sociedad y élites eclesiásticas en la España Moderna: 237-287. Cuenca: Universidad de Castilla-La Mancha. Barrio Gonzalo, M. 1996. «El clero diocesano: beneficios y beneficiados», en Historia de la diócesis de Valladolid: 123-150. Valladolid: Diputación de Valladolid. Fernández Conde, F. J. 1994. La Iglesia de Asturias en la Baja Edad Media. Estructuras económico-administrativas en el tardomedievo. Oviedo: Instituto de Estudios Asturianos. García y García, A. 1996. «Parroquia, arciprestazgo y arcedianato: origen y desarrollo». Memoria Ecclesiae VIII: 19-40. Mollat, G. 1921. La collation des bénéfices eclésiastiques sous les papes d'Avignon. París: Fontemoing \& cie. Martín, J. L. 1975. «Diezmos eclesiásticos: notas sobre la economía de la sede zamorana (siglos XII-XIII), en Actas de las I Jornadas de Metodología Aplicada de las Ciencias Históricas, Vol. 2: 69-78. Madrid: Fundación Universitaria Española. De Reina, V. 1965. El sistema beneficial. Pamplona: Universidad de Navarra. Rodríguez Molina, J. 1986. El Obispado de Baeza-Jaén. Organización y economía diocesanas (siglos XIII-XVI). Jaén: Diputación Provincial de Jaén. Sempere y Guarinos, J. 1822. Historia de las rentas eclesiásticas de España. Madrid: Imprenta de I. Sancha. Torres Gutiérrez, A. 2000. Iglesia y fisco en la Historia de España. Madrid: Universidad Complutense.

${ }^{9}$ Sanz Sancho, I. 2006. La Iglesia de Córdoba (1236-1454). Una diócesis de la provincia eclesiástica de Toledo en la Baja Edad Media: 271. Madrid: Fundación Ramón Areces.

${ }^{10}$ Sánchez Herrero, J. 1992. «La diócesis de Sevilla entre finales del siglo XVI y comienzos del XVII. Las visitas ad limina de los arzobispos de Sevilla D. Rodrigo de Castro, 1597, y D. Fernando Niño de Guevara, 1602 y 1605». Isidorianum 1: 233-261. Sánchez Herrero, J. 1994. «La vida eclesiástica y la religiosidad cristiana en Écija en el paso del siglo XVI al XVII», en Luis Vélez de Guevara y su época. IV Congreso de Historia de Écija: 179-205. Sevilla: Fundación el Monte. Sánchez Herrero, J. 2003. «El clero, la organización eclesiástica y la religiosidad cristiana en Carmona durante los siglos XVI al XVIII», en Carmona en la Edad Moderna: 427-462. Carmona: Ayuntamiento de Carmona.
} 
En las parroquias de la diócesis de Sevilla, entre los siglos XIII al XVII, no existió de manera institucional «cura» alguno, sino que todos fueron beneficiados entre cuyas obligaciones nunca entraba, de forma institucional, la cura animarum. El cumplimiento de este oficio lo hacían los beneficiados libre y voluntariamente. Por eso, en la mayoría de los casos, no lo hacían.

Para confirmarlo, veamos lo que afirma el licenciado Alonso Sánchez Gordillo, ${ }^{11}$ su Memorial Sumario de los Arzobispos de Sevilla, cuando habla «del cabildo y clero de Sevilla y su Arzobispado»:

«Señaló este Prelado las Rentas Dezimales del Arzobispo y Cabildo y las diuidió por medio, aunque en éste después a auido algunas novedades, por tener como tiene el Cabildo la administraçión dellas y los hacimientos de los que se saca sus aprobechamientos y les está a bien a todos los interesados. Ordenó que ninguno fuese recebido en el Cabildo si no fuese graduado de Doctor en Theología o Leyes o Cánones. Que el Arçobispo que por tiempo que se no pudiese dar ninguna dignidad a ninguno que no fuese Prebendado, no embargante que parte de las Dignidades no se requiriere. Hizo, assí mismo, diuisión de los clérigos de las Parroquias y conforme a los términos y poblasión de vecinos que cada vna tenía, puso número de ministros que la siruiesen, a los quales llamó cleros parrochiales, no envargante que reservó para sí el ser Cura Uniuersal, como de derecho le compete, y goza por ello de las rentas de su Arçobispado dezimales e prediales, pues el obispo es Beneficio curado, y que de derecho le incumbe la Cura general de las almas de todo el obispado, quien tenga o no tenga curas propios en él, y mucho más no teniéndolos, como no los ay en este Arzobispado. Y ésa es la eminencia y superioridad del Arçobispado que él, como Vniuersal Cura, puede poner a su arbitrio quien quisiere en su ayuda, y assí puso a Cada Vna de las yglesias parrochiales tanto número de clérigos, quantos bastasen para cada vna, /82v. y esto verisímil que les encomendó la cura, no obstante que no estubiesen obligados a ello, aunque esto después de la mudança de los tiempos a tenido diferente progreso y las cosas se an trocado y alterado, de suerte que oy no se acude por ellas a la dicha cura, sino a voluntad del Prelado y de aquéllos o de otros clérigos indiferentemente; y desta guisa ordenó las yglesias de la ciudad y de todo el Arçobispado».

El número de beneficiarios en las parroquias sevillanas dependían de la cuantía de sus rentas. Eran simples beneficiados, ninguno de ellos beneficiado cura, ${ }^{12}$ aunque utilizasen el título de curas, popular e indistintamente y, como sucede en la documentación estudiada, se les diese este título, aunque no estaban obligados a la cura de almas. Esto dio lugar a que las parroquias sevillanas, pese a estar dotadas de los beneficios económicos más altos de España, estuvieran en muchas ocasiones desatendidas por sus clérigos. Los arzobispos de Sevi-

${ }^{11}$ Sánchez Gordillo, A. 2002. Memorial Sumario de los Arzobispos de Sevilla y otras obras: 176-178. Sevilla: Ayuntamiento de Sevilla.

12 Sánchez Herrero, J. 1998. «La Iglesia y la religiosidad en la Huelva Medieval», en Huelva en la Edad Media. Reflexiones aportaciones y nuevas perspectivas veinte años después: 155. Huelva: Universidad de Huelva. Sánchez Herrero, J. 1992: 233-243. Sánchez Herrero, J. 1994: 181-184. Sánchez Herrero, J. 2003. 427-462

Hispania Sacra, LXIV

130, julio-diciembre 2012, 497-523, ISSN: 0018-215X, doi: 10.3989/hs.2012.015 
lla, ya en el siglo XIII, necesitaron contratar como curas parroquiales a clérigos que no percibían beneficio alguno, muchas veces mal preparados, a los que el arzobispo daba una pequeña cantidad procedente de otros ingresos y conforme a sus posibilidades.

\section{LOS BENEFICIOS PARROQUIALES SEVILLANOS}

Atendiendo a estas premisas, definimos ahora los beneficios parroquiales sevillanos. El beneficio es un término de origen feudal que designa la renta o remuneración del cargo. ${ }^{13}$ El canon 1409 del Código de Derecho Canónico del año 1917 lo define así: «el beneficio eclesiástico es una entidad jurídica constituida o erigida a perpetuidad por la competente autoridad eclesiástica, que consta de un oficio sagrado y del derecho a percibir las rentas anejas por la dote del oficio».

Pueden distinguirse cuatro elementos en el beneficio eclesiástico. Dos, de carácter externo: la creación por la autoridad eclesiástica competente, elemento del que prescindimos para la Edad Media, y la perpetuidad. Los otros dos, de orden interno: el oficio sagrado o eclesiástico y el derecho a percibir las rentas generadas por los bienes del beneficio.

Oficio sagrado o eclesiástico del beneficio no debe entenderse el cuidado y atención pastorales, la administración de los sacramentos a los feligreses de la parroquia. Se reduce a la atención a los actos de culto que se celebraban en la iglesia parroquial: misas, procesiones, horas de Oficio Divino, etc.

Beneficiado es todo clérigo cuya primera, principal y única obligación, similar a la de los canónigos de la catedral, eran las propias de la celebración del oficio sagrado en las iglesias parroquiales. Eso incluía la misa diaria, especialmente, los domingos. Ese día y en los otros festivos se cantaba las Vísperas solemnes. No estando obligado a la administración de los sacramentos a los feligreses o cura pastoral, si era presbítero, podía realizarlo. Aunque se les llamaba cura, no lo eran jurídicamente.

El soporte económico de los beneficios parroquiales lo constituyeron un conjunto de bienes muebles e inmuebles, rústicos y urbanos, y especialmente los diezmos que pagaban los feligreses de cada parroquia o collación. Un tercio de los diezmos se distribuía entre los clérigos beneficiados de cada parroquia. No se repartía en su integridad entre los beneficiados parroquiales, sino que una parte era para las prestameras, destinadas a sustentar a clérigos de la archidiócesis.

\footnotetext{
${ }^{13}$ Martín, J. L. 2005. «Beneficios y oficios del clero rural castellano (siglos XIII-XV)». Anuario de Estudios Medievales 35, 2: 693.
} 
Los beneficios sevillanos fueron tan ricos que de un mismo beneficio participaron dos o tres clérigos distintos:

- Beneficio y beneficiado propietario del mismo: es el clérigo que ha recibido un nombramiento jurídico y legal como titular del beneficio y lo disfruta perpetuamente. Afirma José Sánchez Herrero que en el siglo XV ocurrían «dos hechos extraños». El clérigo beneficiado en propiedad, auténtico beneficiado o beneficiado titular, no tenía obligación de servir personalmente el beneficio, es decir, de cumplir las obligaciones propias del oficio sagrado o eclesiástico correspondiente. Lo podía hacer por medio de una segunda persona a quien se denomina beneficiado servidero o clérigo servidero de un beneficio. La mayor parte de las rentas del beneficio las percibía el beneficiario propietario y sólo una pequeña parte el clérigo servidero de un beneficio o el beneficiado servidero.

El beneficiado titular no tenía necesariamente que ser un clérigo residente en la ciudad donde radicaba el beneficio. Podía ser un clérigo ausente, diocesano o extra-diocesano, e incluso una institución clerical, convento, capilla, colegio religioso, cabildo catedral, etc. Se deduce la del segundo clérigo que participaba del beneficio junto al beneficiado titular: el beneficiado servidero.

- Beneficiado servidero: es el clérigo que sirve las obligaciones propias del oficio del beneficio o beneficiado en propiedad, pero que sólo cobra una parte más pequeña de las rentas del beneficio.

- Administrador del beneficio: es el clérigo o laico, nombrado por el beneficiado titular o en propiedad, para que le administre las rentas del beneficio.

La documentación corrobora las definiciones establecidas por Sánchez Herrero. Hemos estudiado un total de nueve documentos relacionados con los beneficios y distintos negocios de que son objeto. Sorprende la idea de los beneficios que tienen las personas a ellos vinculados. En ocasiones se pierde su naturaleza eclesiástica y adquieren un carácter público y mundano. Prueba de ello es que son negocios ratificados por la fe pública de los escribanos y no rubricados por una autoridad propiamente eclesiástica.

Como puede observarse, la jerarquía humana de ciertos beneficios establecida por Sánchez Herrero queda perfectamente ejemplificado en los 12 casos estudiados, con la incorporación de su administrador. ${ }^{14}$ En cinco documentos el negocio al que el beneficio se somete es el contrato por parte del beneficiado titular, o del administrador en su lugar, con un beneficiado servidero. Los contratados son cuatro clérigos sin más y un clérigo presbítero. Uno de estos beneficiados servideros, Ruy López, de Alcalá de Henares, firma el contrato para actuar como capellán. Los sueldos asignados a cambio de estos servicios oscilan entre los 600 maravedís y los 1.500 maravedís, a los que, en dos casos,

\footnotetext{
14 Véase tabla.
} 
se añade el complemento de los pies de altar y otros ingresos no especificados. No puede establecerse una norma general para la vigencia de los contratos, dada la escasez de los ejemplos disponibles. La documentación estudiada la fijan en un año cuatro contratos y uno en dos años.

El resto de los documentos están relacionados con las rentas del beneficio en lo que se refiere a cuestiones sobre las propiedades anexas, como arrendamiento de casas, cobro de los bienes generados, poderes a los administradores para ello, arrendamiento de los ingresos, siendo en los dos ejemplos recogidos el administrador quien lo hace, sueldo pagado al administrador por su trabajo, y

\begin{tabular}{|c|c|c|c|}
\hline $\begin{array}{l}\text { Beneficiado titular/ } \\
\text { localización del beneficio }\end{array}$ & $\begin{array}{l}\text { Beneficiado } \\
\text { servidero }\end{array}$ & $\begin{array}{l}\text { Administrador } \\
\text { del beneficio }\end{array}$ & $\begin{array}{l}\text { Negocio de que es } \\
\text { objeto el beneficio }\end{array}$ \\
\hline $\begin{array}{l}\text { Pedro Rodríguez/ } \\
\text { San Ildefonso }{ }^{15}\end{array}$ & $\begin{array}{l}\text { Ruy López de Al- } \\
\text { calá de Henares, } \\
\text { clérigo presbítero }\end{array}$ & & $\begin{array}{l}\text { El titular contrata al servi- } \\
\text { dero para servir como cape- } \\
\text { llán durante un año por } 600 \\
\text { maravedís }\end{array}$ \\
\hline $\begin{array}{l}\text { Andrés Fernández } \\
\text { /Aznalcázarir }\end{array}$ & $\begin{array}{l}\text { Benito Rodrí- } \\
\text { guez, clérigo }\end{array}$ & & $\begin{array}{l}\text { El titular contrata al servi- } \\
\text { dero para servir en el bene- } \\
\text { ficio por dos años y } 2.800 \\
\text { maravedís más un cahíz de } \\
\text { trigo }\end{array}$ \\
\hline $\begin{array}{l}\text { (hueco) de Villamar- } \\
\text { tín/San Andrés }{ }^{17}\end{array}$ & & $\begin{array}{l}\text { Pedro Sánchez de } \\
\text { Santo Domingo, } \\
\text { racionero }\end{array}$ & $\begin{array}{l}\text { Ruptura de contrato de } \\
\text { arrendamiento de unas casas } \\
\text { del beneficio, nuevo arren- } \\
\text { damiento de las mismas }\end{array}$ \\
\hline $\begin{array}{l}\text { Antón de León/ San- } \\
\text { ta Catalina }{ }^{18}\end{array}$ & $\begin{array}{l}\text { Juan de Cazalla, } \\
\text { clérigo }\end{array}$ & $\begin{array}{l}\text { Pedro González, } \\
\text { clérigo }\end{array}$ & $\begin{array}{l}\text { El administrador contrata al } \\
\text { beneficiado servidero por un } \\
\text { año y } 1.500 \text { mrs. más el pie } \\
\text { de altar y aventuras }\end{array}$ \\
\hline $\begin{array}{l}\text { Juan de Valagar, ra- } \\
\text { cionero/ Conilejo } 19\end{array}$ & & $\begin{array}{l}\text { Francisco de Jerez, } \\
\text { clérigo de Vejer }\end{array}$ & $\begin{array}{l}\text { En nombre del titular se da } \\
\text { poder para cobrar las rentas } \\
\text { del beneficio al adminis- } \\
\text { trador }\end{array}$ \\
\hline $\begin{array}{l}\text { Alfonso Toribio, clé- } \\
\text { rigo/ Santa } \mathrm{M}^{\mathrm{a}} \text { de } \\
\text { (roto) }{ }^{20}\end{array}$ & & Alfonso Sánchez & $\begin{array}{l}\text { El administrador arrienda } \\
\text { las rentas del beneficio a } \\
\text { Juan Ferrández, capellán }\end{array}$ \\
\hline
\end{tabular}

\footnotetext{
${ }^{15}$ Leg. 2154. Fol. 335v.

${ }^{16}$ Leg. 9101 . Fol. 114v.

${ }^{17}$ Leg. 2161. Fol. 204r.

${ }^{18}$ Leg. 3213. Fol. 21r.

${ }^{19}$ Leg. 2154. Fol. 223r.

${ }^{20}$ Leg. 3210. Fol. 66v.
} 


\begin{tabular}{|c|c|c|c|}
\hline $\begin{array}{l}\text { Beneficiado titular/ } \\
\text { localización del beneficio }\end{array}$ & $\begin{array}{c}\text { Beneficiado } \\
\text { servidero }\end{array}$ & $\begin{array}{l}\text { Administrador } \\
\text { del beneficio }\end{array}$ & $\begin{array}{l}\text { Negocio de que es } \\
\text { objeto el beneficio }\end{array}$ \\
\hline $\begin{array}{l}\text { Antón de León, cléri- } \\
\text { go/ Santa Catalina }{ }^{21}\end{array}$ & $\begin{array}{l}\text { Juan de Cazalla, } \\
\text { clérigo }\end{array}$ & $\begin{array}{l}\text { Pedro González, } \\
\text { clérigo }\end{array}$ & $\begin{array}{l}\text { El administrador contrata al } \\
\text { servidero para servir en el } \\
\text { beneficio durante un año } \\
\text { por } 1.500 \text { maravedís más el } \\
\text { pie de altar y aventuras }\end{array}$ \\
\hline $\begin{array}{l}\text { Diego Bermúdez, } \\
\text { abad de San Salva- } \\
\text { dor/Santa Ana } 22\end{array}$ & & $\begin{array}{l}\text { Pedro Bermúdez, } \\
\text { hermano del titular }\end{array}$ & $\begin{array}{l}\text { El administrador arrienda } \\
\text { las rentas del beneficio a } \\
\text { Alfonso Pérez de las Heras, } \\
\text { cura de Santa Ana }\end{array}$ \\
\hline $\begin{array}{l}\text { Cristóbal Caro, cléri- } \\
\text { go/ Santiago }{ }^{23}\end{array}$ & & Pedro de Talavera & $\begin{array}{l}\text { El titular da poder al admi- } \\
\text { nistrador para cobrar ciertas } \\
\text { rentas del beneficio }\end{array}$ \\
\hline $\begin{array}{l}\text { Antón de León/ Santa } \\
\text { Catalina24 }\end{array}$ & $\begin{array}{l}\text { Pedro González, } \\
\text { clérigo }\end{array}$ & $\begin{array}{l}\text { Juan de Cazalla, } \\
\text { clérigo }\end{array}$ & $\begin{array}{l}\text { Administrador contrata al } \\
\text { servidero por un año y } \\
1.500 \text { mrs. más el pie de al- } \\
\text { tar y aventuras }\end{array}$ \\
\hline $\begin{array}{l}\text { Alfonso Lobo, cléri- } \\
\text { go/ S. Bartolomé } \\
\left.\text { (Carmona }{ }^{25}\right)\end{array}$ & & $\begin{array}{l}\text { Juan Rodríguez, } \\
\text { clérigo }\end{array}$ & $\begin{array}{l}\text { Poder del titular al adminis- } \\
\text { trador para cobrar las rentas }\end{array}$ \\
\hline $\begin{array}{l}\text { Francisco de Orvane- } \\
\text { ja/ El Puerto de Santa } \\
M^{\mathrm{a}} \text { y San Juan de } \\
\text { Écija }^{26}\end{array}$ & & $\begin{array}{l}\text { Pedro Fernández } \\
\text { de Benadena, ma- } \\
\text { yordomo del cabil- } \\
\text { do }\end{array}$ & $\begin{array}{l}\text { El titular paga al arrendador } \\
\text { lo que le debía de ciertos } \\
\text { arrendamientos que le hizo } \\
\text { del beneficio }\end{array}$ \\
\hline
\end{tabular}

otorgamiento de poder con plenos derechos. Esta actuación supone una equiparación de las rentas del beneficio a otros impuestos como los concejiles, que se arriendan a una serie de personas, normalmente tras un proceso de puja en almoneda pública. El titular que se beneficia de esas rentas o de esos impuestos recibe una cantidad determinada y se libera de la responsabilidad de recaudarlos y cobrarlos, ocupándose de ello el arrendador.

El titular de un beneficio no tenía que residir en el lugar donde estaba creado el mismo. Eso ocurre en los casos los clérigos residentes en Sevilla: Andrés Fernández con su beneficio en Aznalcázar, Juan de Valagar en el Conilejo, Al-

\footnotetext{
${ }^{21}$ Leg. 3213. Fol. 21r.

${ }^{22}$ Leg. 2163. Fol. 72r.

${ }^{23}$ Leg. 2155. Fol. 634r.

${ }^{24}$ Leg. 3213. Fol. 21r.

${ }^{25}$ Leg. 2161. Fol. 33r.

${ }^{26}$ Leg. 2154. Fol.3 18v.
} 
fonso Lobo, en San Bartolomé de Carmona, y Francisco de Orvaneja, en El Puerto de Santa María y San Juan de Écija. El resto de los beneficios, objeto de algún negocio, estaban en iglesias donde residían sus titulares: San Andrés, San Ildefonso, Santa Ana, Santa Catalina y Santiago. En un caso no es posible indicar dónde se sitúa una parroquia de advocación mariana, Santa María, por hallarse el documento deteriorado. Puede tratarse de la Catedral de Sevilla.

La documentación muestra el procedimiento de toma de posesión de su beneficio. Vemos la de Antón Rodríguez, quien recibió del Papa un beneficio en la iglesia de San Isidoro, ${ }^{27}$ vacante por muerte del anterior titular. Se abrió la bula de concesión, sellada con el sello de plomo. A continuación, en señal de verdadera posesión e corporal tomó asiento sobre el escaño situado en el lugar donde se suelen sentar los otros beneficiados, cogió un libro entre las manos y rezó sobre el mismo. Finalmente, descendió al altar mayor, echó por el suelo unas blancas ${ }^{28}$ que traía en la mano e quedó en él pacíficamente.

Hemos de añadir que es un caso de un beneficiado nombrado por la Santa Sede, pero lo habitual es que lo hiciera el obispo diocesano. Se trata de un beneficio parroquial, sin obligación de cura de almas. Por eso en el ceremonial aquí descrito no hay visita del altar, del sagrario, de la pila bautismal, símbolos de la administración de los sacramentos o cura pastoral.

\section{UNIVERSIDAD DE BENEFICIADOS}

La universidad de beneficiados de Sevilla, como la de otros lugares, fue un instituto eclesiástico reconocido por el Derecho Canónico, dotado de una personalidad jurídica colectiva y constituido por todos los clérigos beneficiados propios del lugar. Sometida a la autoridad legal y disciplinar del arzobispo, contaba con estatutos que regulaban, entre otras cuestiones, el cumplimiento de la disciplina interna, la gestión de los bienes propios, o la posición jerárquica de sus miembros.

Desde los años del arzobispado de don Remondo, ${ }^{29}$ el clero beneficial de Sevilla se reunió en el cabildo de beneficiados o clerecía, cofradía clerical, que

\footnotetext{
${ }^{27}$ Leg.19725. Fol.76v.

${ }_{28}$ Para una evaluación de la blanca y su relación con otras monedas en el siglo XV, Mackay, A. 2006. Moneda, precios y política en la Castilla del siglo XV. Granada: Universidad de Granada. Ladero Quesada, M. A. 1982. «Moneda y tasa de precios en 1462. Un episodio ignorado en la política económica de Enrique IV de Castilla», en El siglo XV en Castilla. Fuentes de renta y política fiscal: 114-142. Barcelona: Ariel.

${ }^{29}$ Sánchez Herrero, J. 2008. Historia de la Iglesia en España e Iberoamérica: desde sus incicios hasta el siglo XX: 147. Madrid: Sílex.
} 
también existió en las parroquias castellano-leonesas ${ }^{30}$ En Andalucía recibió el nombre de Universidad de clérigos, dirigida por un abad, en el caso de Sevilla denominado el Abad Mayor de Sevilla.

En el año 1499 y hasta 1502 desempeñó este cargo Antón de Cueva, beneficiado de la iglesia de San Vicente. ${ }^{31}$ La Universidad de clérigos de Sevilla, como otras similares, estaba regida por unos estatutos o constituciones propias. Afirma Sánchez Herrero que, en sus primeros tiempos, la Universidad tenía sus reuniones en la parroquia de San Juan de la Palma, su sede hasta el Concilio del Vaticano II.

A fines del siglo XV y a principios del XVI da la impresión de que no contaba con un lugar fijo para reunirse, si bien mantenía jurídicamente su sede en San Juan de la Palma, pues hemos documentado sesiones de la Universidad en la iglesia de Omnium Sanctorum el ocho de febrero de 1499, ${ }^{32}$ en la iglesia de San Martín el dos de julio de $1500^{33}$ y en la colegiata de El Salvador el nueve de agosto de 1502.34

La Universidad de beneficiados de Sevilla poseía su propio patrimonio, ciertos derechos parroquiales, en alguna parte, los diezmos y los diezmos y en los tributos que pagaban los judíos y moros de cada collación, hasta su expulsión. En 1271 Alfonso X eximió de pagar tributos a todos sus miembros y les otorgó permiso para vender y comprar cualquier tipo de heredad, a cambio de un conjunto de aniversarios y otras fiestas a lo largo del año por la familia real.

Con el tiempo la Universidad llegó a adquirir un enorme poder económico y jurídico en la ciudad y su entorno. La Universidad de beneficiados de Sevilla acudió a las escribanías públicas para realizar con sus bienes distintos negocios. La documentación ha permitido conocer estas propiedades, los lugares de reunión y la nómina de beneficiados que ocupaban una posición más destacada dentro de ella, con las consiguientes competencias.

Puede verse esto en la siguiente tabla:

\footnotetext{
${ }^{30}$ González Jiménez, M. 1974. «Archivo de la Universidad de Beneficiados de Carmona. Catálogo de documentación medieval». Historia, Instituciones y documentos 1: 361-387. González Jiménez, M. 1975. «La Universidad de beneficiados de Carmona. Estudio de la formación de una gran propiedad eclesiástica» en Actas de las I Jornadas de Metodología aplicada a las Ciencias Históricas. Historia Medieval, v.II: 155-159. Santiago de Compostela: Universidad de Santiago. Osorio Muñoz, M. 1984. «El bajo clero en Jaén en el tránsito a la Edad Moderna. La Universidad de Curas Párrocos», en Actas del III Coloquio de Historia Medieval Andaluza: grupos no privilegiados: 457-471. Jaén: Diputación Provincial de Jaén. Parejo Delgado, M.J. 1982. «Los estatutos de la Universidad de clérigos beneficiados de Arjona (1488). Textos y comentarios», en Actas del I Coloquio de Historia de Andalucía. Andalucía Medieval: 369-382. Córdoba: Diputación Provincial de Córdoba. Sanz Sancho, I. 2006. La Iglesia de Córdoba..., ob. cit., pp.324-345.

${ }^{31}$ Leg. 1500. Fols. 294v., 369v. Leg. 2158. Fol. 130r. Leg.3 219. Fol.8r. Leg. 19725. Fols. 58r.

${ }^{32}$ Leg. 17425. Fol. 58r.

33 Leg. 2158. Fol. 130r.

${ }^{34}$ Leg. 1500. Fol. 369v.
} 


\begin{tabular}{|c|c|c|c|c|c|c|c|c|c|c|c|c|c|c|c|c|c|c|c|}
\hline 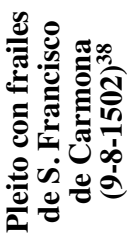 & $x$ & $x$ & $x$ & & & & $x$ & & & & $x$ & $x$ & $x$ & & $x$ & $x$ & $x$ & $x$ & \multirow{2}{*}{ 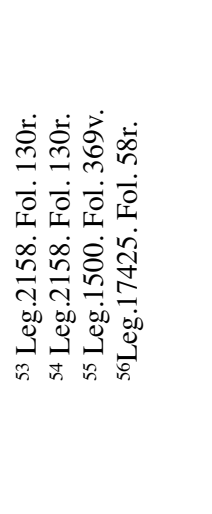 } \\
\hline 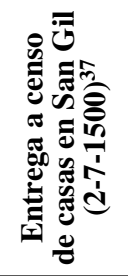 & $x$ & $x$ & $x$ & $x$ & & $x$ & $x$ & & $x$ & $x$ & & & $x$ & & $x$ & & & $x$ & \\
\hline 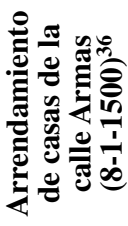 & $x$ & $x$ & $x$ & $x$ & $x$ & $x$ & $x$ & & $x$ & $x$ & & & $x$ & & $x$ & $x$ & & $x$ & 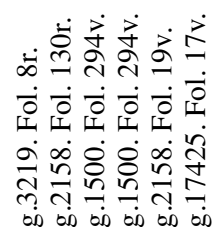 \\
\hline 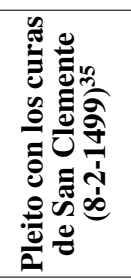 & $x$ & $x$ & & & & $x$ & $x$ & $x$ & & $x$ & & & & $x$ & $x$ & & & $x$ & 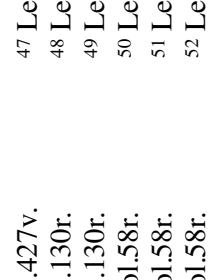 \\
\hline 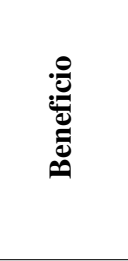 & 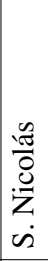 & 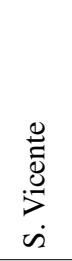 & 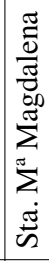 & 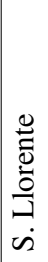 & 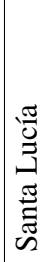 & 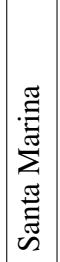 & 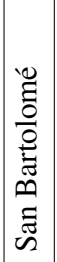 & 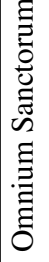 & 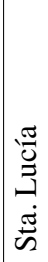 & 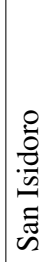 & 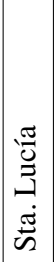 & 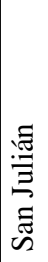 & 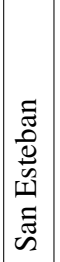 & 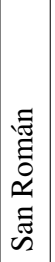 & 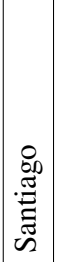 & 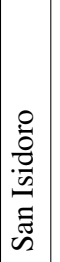 & 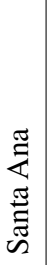 & $\begin{array}{l}0 \\
0 \\
\tilde{0} \\
\frac{0}{0} \\
\frac{0}{0} \\
\Xi \\
\tilde{\Xi} \\
\tilde{n}\end{array}$ & 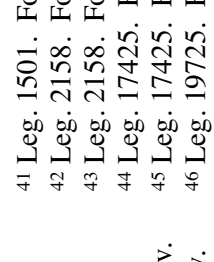 \\
\hline 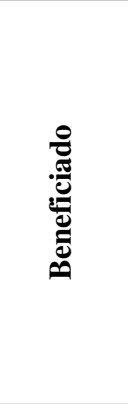 & 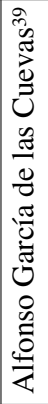 & 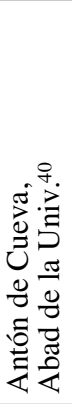 & 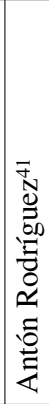 & 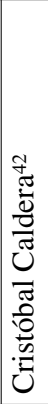 & 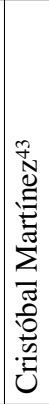 & 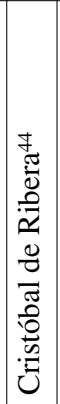 & 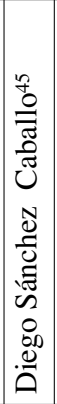 & 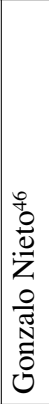 & 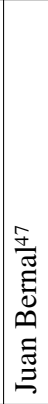 & 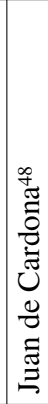 & 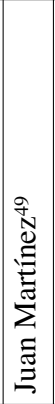 & 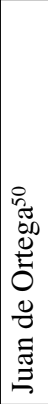 & 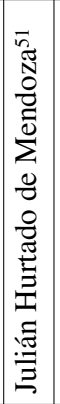 & 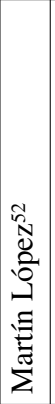 & 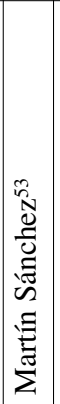 & 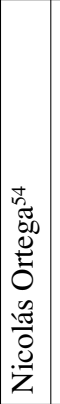 & 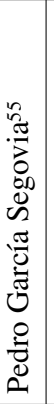 & 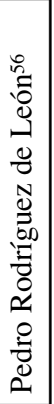 & 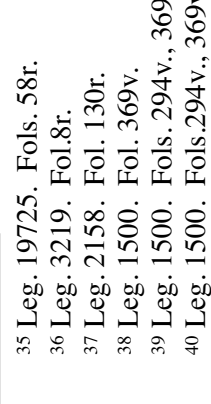 \\
\hline
\end{tabular}


Esta nómina de beneficiados debió formar una especie de junta de gobierno de toda la Universidad, para tramitar los asuntos de la institución. Entre ellos se encuentran dos pleitos, uno con los curas de la capilla de San Clemente y el otro, con el monasterio de San Francisco de Carmona. Se desconoce los motivos de éste último. En cambio, el litigio con los curas de San Clemente fue con motivo de las exequias de Pedro Ponce, celebradas en la capilla. Los beneficiados de la Universidad tomaron una ofrenda y, por eso, los acusaron los curas de San Clemente y fueron objeto de una serie de agravios.

La reunión de los beneficiados de la Universidad celebrada en la iglesia de Omnium Sanctorum fue para tratar sobre el otorgamiento de un poder a Antón Rodríguez, beneficiado de la iglesia de San Marcos. Éste y un laico, de su mismo nombre (pura coincidencia o error del escribano), representarán a la Universidad en el proceso abierto. No es extraño este tipo de asuntos protagonizados por la Universidad, pues en muchas ocasiones se enfrentó y mantuvo largos pleitos con el arzobispo y con otras instituciones eclesiásticas, ${ }^{57}$ como la habida con los frailes de San Francisco. Las cuestiones relacionadas con propiedades generaron muchas disputas.

En el patrimonio de la Universidad podemos distinguir casas, censos y tierras. Las casas eran la parte predominante..$^{58}$ Aseguraban rentas fijas y estaban situadas en la ciudad. Esto facilitaba su gestión, sin tener que desplazarse. Hay documentos sobre unas casas en San Vicente, en la calle de Armas, ${ }^{59}$ arrendadas por tres vidas y una renta anual de 900 maravedís; 60 en la de en San Ildefonso; 61 las de San Gil fueron alquiladas por una vida y por de 1.000 maravedíes y dos pares de gallinas entregadas ocho días antes de Pascua de Navidad.

La documentación no aporta mucho sobre el tipo casas. En la mayoría de los casos, son unos palacios, sobrados y corral. Nada se indica sobre su tamaño,

57 Sánchez Herrero, J. 2008. 148.

58 Collantes de Terán Sánchez, A. 1989. «El mercado inmobiliario en Sevilla (Siglos XIII-XV)», en D’une Ville à L'autre: Structures Matérielles et Organisation de L'espace dans les Villes Européennes (XIII-XVI Siècle). Actes du Colloque organisé par l'Ecole française de Rome: 227-242. Roma: 1'Ecole française de Rome. Collantes de Terán Sánchez, A. 2007. «El modelo meridional: Sevilla», en XXXIII Semana de Estudios Medievales de Estella. Mercado inmobiliario y paisajes urbanos en el occidente europeo: siglos XI-XV: 591-630. Pamplona: Gobierno de Navarra.

${ }^{59} \mathrm{La}$ Universidad de beneficiados, al igual que el resto de los habitantes de la ciudad, se veía favorecida por el momento de auge económico que vivía la Sevilla del otoño Medieval, a diferencia de lo que sucederá en Época Moderna, cuando numerosas propiedades inmobiliarias estaban sin habitar, pues sus moradores habían caído en la más completa miseria y no podían pagar los alquileres, viéndose obligados a tener que desalojarlas y no lográndose arrendar de nuevo (Carmona García, J. I. 1993. El extenso mundo de la pobreza: la otra cara de la Sevilla Imperial: 35. Sevilla: Ayuntamiento de Sevilla.

${ }^{60}$ Collantes de Terán Sánchez, A. 1999. «Moneda y cambios en la Sevilla bajomedieval», en Dinero, moneda y crédito en la monarquía hispánica: actas del Simposio Internacional «Dinero, moneda y crédito: de la monarquía hispánica a la integración monetaria Europea»: 59-82. Madrid: Fundación ICO.

${ }^{61}$ Leg. 1497. Fol. 42v. 
que no es posible fijar a partir de las rentas fijadas en los contratos de arrendamiento. En las cantidades a pagar por los inquilinos debieron influir otros factores, además de las proporciones de las casas: la situación en la ciudad y dentro de la collación, el estado de conservación, el disponer de alguna infraestructura especial, los materiales constructivos, etc.

La predilección por los alquileres por un periodo de tiempo prolongado puede obedecer a varios motivos. En primer lugar, evidencia la inexistencia de un control exhaustivo de la economía. Con estos contratos de una y tres vidas, la Universidad buscaba asegurarse rentas fijas durante largo tiempo, sin necesidad de revisar los contratos o confeccionar otros nuevos. Eso suponía que los alquileres permaneciesen fijos muchos años, sin que les afectara el incremento del coste de la vida. No hay un afán de lucro. El cobro regular de unas rentas costeaban las actividades de la Universidad de Beneficiados.

El segundo grupo de bienes que integraban el patrimonio beneficial universitario eran los censos. ${ }^{62}$ Incluidos dentro de los sistemas de crédito vigentes en la época, la Universidad contaba con un censo de 500 maravedíes en unas casas en la Magdalena. ${ }^{3}$ Fueron donadas por Bartolomé Martel a cambio de que los beneficiados de la Universidad acompañasen su cuerpo a enterrar y le hiciesen celebrar cada año una fiesta de la Encarnación de Nuestro Señor en la iglesia de la Magdalena. ${ }^{64}$

El patrimonio de la Universidad de beneficiados lo completaban unas tierras, ${ }^{65}$ concretamente una aranzada de viñas ${ }^{66}$ en el Pago de San Román de Triana, arrendadas por 500 maravedíes y una gallina. El inquilino, al no poder pagar la renta, rompió el contrato. Pero inmediatamente se firmó un contrato ${ }^{67}$ con uno nuevo, por la misma cantidad de dinero pero con un incremento en el pago en gallinas que ascendió a tres. ${ }^{68}$

En el cuadro se observa la presencia regular de los beneficiados en cada uno de los negocios. A todos ellos asistió el abad, Antón de Cueva. También lo hi-

62 Borrero Fernández, M. 2003. «Efectos del cambio económico en el ámbito rural. Los sistemas de crédito en el campo sevillano (fines del siglo XV y principios del XVI)», en Mundo rural y vida campesina en la Andalucía medieval: 40-41. Granada: Universidad de Granada.

${ }^{63}$ Leg. 1499. Fol. 350v.

64 Pérez González, S. M. 2005. Los laicos en la Sevilla bajomedieval. Sus devociones y cofradías: 89-102. Huelva: Universidad de Huelva.

65 Collantes de Terán Sánchez, A. 1979. «Génesis de la gran propiedad en la Baja Edad Media. La propiedad eclesiástica sevillana», en La economía agraria en la Historia de España: 133-140. Madrid: Fundación Juan March.

66 Sinecuras: Sanz Sancho, I. 2006: 291

${ }^{67}$ Leg. 1500. Fol. 294v.

${ }^{68}$ Generalmente se fijaba como momento de entrega de las aves ocho días antes de Navidad, lo cual es indicativo de la importancia con que se celebraba el nacimiento de Cristo o que en invierno había que tomar buen caldo caliente 
cieron Diego Sánchez Caballo, Martín Sánchez y Pedro Rodríguez de León. En el extremo opuesto, con una sola asistencia, estarían Cristóbal Martínez, Gonzalo Nieto, Juan Martínez, Juan de Ortega, y Martín López. Finalmente, en este grupo dirigente de la Universidad no había representantes de cada una de las parroquias o, al menos, la documentación estudiada no lo recoge. En la nómina presentada están ausentes las parroquias de San Andrés, San Gil, San Juan de la Palma, San Marcos, San Martín, San Miguel, San Pedro, Santa Catalina y Santa María.

\section{PRÉSTAMOS O PRESTAMERAS}

Existió en la diócesis de Sevilla un beneficio prestamero o prestamera. ${ }^{69}$ Quien lo gozaba no estaba obligado a ningún tipo de servicio u otro deber en la parroquia donde se hallaba constituido. Las rentas de la prestamera, al igual que las del beneficio, procedían del tercio de los diezmos parroquiales asignados a los beneficiados, pero no se repartían íntegramente entre ellos, sino que en todas las parroquias se dejaba una parte para estos préstamos, prestameras o beneficios prestameros.

La mayor parte de las prestameras eran asignadas por el arzobispo a clérigos de la archidiócesis. Pero en repetidas ocasiones se asignaron a clérigos o instituciones extra-diocesanos. En algunos casos los beneficiarios no tuvieron título de beneficiado o beneficio parroquial o, aunque lo tuvieran, percibían su prestamera por otros servicios como estudiantes en la Universidad literaria, ${ }^{70}$ empleados en otros oficios eclesiásticos, etc.

Había prestameras en casi todas las parroquias, porque era muy raro que los beneficiados percibieran todo el tercio del diezmo. Conocemos el cuadro completo de todas las prestameras de la diócesis de Sevilla. ${ }^{71}$ La documentación estudiada informa de varias. Las de las iglesias de Las Cabezas y de Gerena eran gozadas por Antón de León. ${ }^{72}$ Están incluidas en la documentación notarial por las deudas de dos vecinos de ambos lugares, contraídas con él. Uno de ellos, Diego Gil, tenía que pagarle dos fanegas y ocho almudes de pan terciado. ${ }^{73} \mathrm{El}$ otro, Francisco López, le debía 8.200 maravedíes de 100 fanegas de cebada, ${ }^{74}$ quizás percibidos de los diezmos de la prestamera.

\footnotetext{
${ }^{69}$ Sánchez Herrero, J. 1998: 156

70 Sanz Sancho, I. 2006: 293

${ }^{71}$ Sánchez Herrero, J. 2008: 126-134.

${ }^{72}$ Leg. 9101. Fol. 74v.

73 Leg. 9101. Fol. 74v.

${ }^{74}$ Leg. 9101. Fol. 639v.
} 
De la prestamera de Omnium Sanctorum era beneficiario en 1493 Fernando Álvarez..$^{75}$ Sabemos que las rentas generadas por la prestamera, al igual que sucedía con el beneficio, las arrendaba su titular. Fernando Álvarez arrendó la suya a Juan de Valladolid. El documento se halla fragmentado, por lo que desconocemos el tiempo y el dinero establecidos en el contrato.

Desconocemos también en cuánto arrendó su prestamera de San Vicente de Alcalá de los Gazules y San Francisco de Tarifa el canónigo Francisco de Morales. ${ }^{76} \mathrm{El}$ documento conservado es un poder dado a su padre, el comendador Cristóbal de Morales, para arrendar las rentas generadas por la prestamera. ${ }^{77}$ No se ha conservado dato alguno de las gestiones hechas.

Clérigos Residentes en SEVILla con un Beneficio en PaRRoQuias de fuera DE LA CIUDAD

No sorprende que vivieran en la ciudad de Sevilla clérigos cuyos beneficios estaban fuera. Estos titulares debieron tener en esos beneficios, distribuidos por diferentes lugares de la diócesis, un beneficiado servidero, es decir, una persona que cumplía por ellos las obligaciones propias del oficio sagrado o eclesiástico, y al que remuneraban con una parte de las rentas percibidas. Quizás algunos beneficiados titulares nunca hicieron acto de presencia en sus parroquias. Un administrador se ocupaba de todas las cuestiones económicas del mismo y el beneficiado servidero, de atenderlo.

La documentación nos informa de la existencia de 19 clérigos residentes en Sevilla cuyos beneficios estaban fuera de la ciudad. Quince sobre diecinueve, en la diócesis y dos en otras: Valaguera, en la de Toledo ${ }^{78}$ y los beneficios de las iglesias de García Fernández (topónimo) y Santa María, en la de Salamanca. ${ }^{79}$ No podemos indicar uno, porque se halla el documentado fragmentado físicamente. Hay casos de evidentes de acumulación de beneficios.

\footnotetext{
75 Leg. 3214. Fol. 6v.

${ }^{76}$ Leg. 2156. Fol. 240v.

77 Leg. 2156. Fol. 240v.

78 Leg. 1497. Fol. 21v.

${ }^{79}$ Leg. 3217. Fol. 152v.
} 


\section{Cuadro de los beneficiados residentes en Sevilla con beneficios fuera de Sevilla, lugar de su beneficio y signatura para su localización en el apéndice.}

\begin{tabular}{|l|l|l|}
\hline \multicolumn{1}{|c|}{$\begin{array}{c}\text { Nombre } \\
\text { del beneficiado }\end{array}$} & \multicolumn{1}{c|}{$\begin{array}{c}\text { Lugar donde } \\
\text { sencuentra el beneficio }\end{array}$} & \multicolumn{1}{c|}{ Signatura } \\
\hline Alfonso Miguel & Valencina & Leg. 2157. Fol. 217r. \\
\hline Alfonso Toribio & Santa María de (roto) & Leg. 3210. Fol. 66v. \\
\hline Andrés Fernández & Aznalcázar & Leg. 1500. Fol. 513r. \\
\hline Antón Martínez & Aznalcázar & Leg. 2158. Fol. 326r. \\
\hline Diego de León & Alanís & Leg. 4886. Fol. 441r. \\
\hline Fernando de Ortega & Santa María de Carmona & Leg. 1500. Fol. 401v. \\
\hline Francisco de Alcalá & Cala & Leg. 1499. Fol. 46v. \\
\hline Francisco de Herrera & S. Bartolomé de Villalva del Alcor & Leg. 1499. Fol. 131r. \\
\hline Francisco de Orvaneja & $\begin{array}{l}\text { El Puerto de Santa María y } \\
\text { San Juan de Écija }\end{array}$ & Leg. 2154. Fol. 318v. \\
\hline Juan Benítez & Bornos y Espera & Leg. 17418. Fol. 54v. \\
\hline Juan de la Cuadra & Gerena & Leg. 2156. Fol. 6v. \\
\hline Juan González & $\begin{array}{l}\text { García Fernández y Santa María } \\
\text { de (roto) en la diócesis de Salamanca }\end{array}$ & Leg. 3210. Fol. 37r. \\
\hline Juan de Padilla & San Miguel de Alcalá de Guadaíra & Leg. 2154. Fol. 771v. \\
\hline Juan Rodríguez & Fregenal & Leg. 17418. Fol. 81v. \\
\hline Juan de Valagar & Conilejo & Leg. 2154. Fol. 223r. \\
\hline Luis del Castillo & Guillena & Leg. 3221. Fol. 114r. \\
\hline Martín de Montiel & Valaguera en la diócesis de Toledo & Leg. 1500. Fol. 25r. \\
\hline Pedro Ferrández de Santaella & Marchena & Leg. 17426. Fol. 166v. \\
\hline
\end{tabular}




\section{ACUMULACIÓN DE BENEFICIOS}

El sistema beneficial pretendía que cada clérigo gozase de un solo beneficio, pero algunos acumularon varios. Eso le proporcionaba mayores rentas, pues disponían de varias fuentes de ingreso. No hablamos, en ningún caso, de beneficiados ricos o pobres, pues en la Edad Media riqueza y pobreza son dos conceptos relativos, establecidos en función del tipo de vida exigido a cada persona de acuerdo con su estatus social. ${ }^{80}$ La normativa canónica ${ }^{81}$ obligaba a la creación de beneficios eclesiásticos con suficiente dotación económica. No todos los beneficios cumplían este requisito. Fue necesario acumular varios beneficios menores en una misma persona hasta alcanzar la cuantía equivalente a un beneficio mayor.

Los clérigos documentados en los que se daba esta situación de acumulación de beneficios son:

Alfonso Lobo: 82 capellán de los reyes en la Catedral y beneficiado de la iglesia de San Bartolomé de Carmona.

Diego Bermúdez: ${ }^{83}$ Abad de San Salvador y beneficiado de la iglesia de Santa Ana de Sevilla.

Diego Martínez de Cala: ${ }^{84}$ Racionero de la Catedral y beneficiado de la iglesia de Santa Ana de Sevilla.

Diego Serrano: ${ }^{85}$ Medio racionero de la Catedral y beneficiado de la iglesia de San Bartolomé de Sevilla.

Fernando Álvarez: ${ }^{86}$ Canónigo de la Catedral, beneficiado de las iglesias de la Magdalena y de San Gil de Sevilla, capellán de la iglesia de Huévar, beneficiado de la iglesia de Niebla, prestamero de la de Omnium Sanctorum de Sevilla, y cobra la pensión del beneficio de la iglesia de Santiago de Sevilla.

Fernando Ruiz de Ojeda: ${ }^{87}$ Capellán de San Salvador y «cura» de la Magdalena de Sevilla.

\footnotetext{
${ }^{80}$ Sanz Sancho, I. 2006: 291

${ }^{81}$ Concilio Nacional de Valladolid de 1322, cánones 9 y 10. Véase: Tejada y Ramiro, J. 1849. Colección de cánones y de todos los concilios de la Iglesia de España y América, tomo III: 486-488. Madrid: Imprenta de D. Pedro Montero. Sánchez Herrero, J. 1978: 174-182

82 Leg. 2161. Fol. 333r.

${ }^{83}$ Leg. 2163. Fol. 72r.

${ }^{84}$ Leg. 3211. Fol. 17v.

85 Leg. 1497. Fol. 498v.

86 Leg. 17418. Fol. 74v.

${ }^{87}$ Leg. 2156. Fol. 18r.
} 
Francisco López:88 Prior y canónigo de San Salvador y beneficiado de la iglesia de San Andrés de Sevilla.

Francisco de Morales: ${ }^{89}$ Racionero de la Catedral y beneficiado de la iglesia de San Andrés de Sevilla.

Francisco Pérez:90 Arcediano de Badajoz y racionero de la Catedral de Sevilla.

Juan Rodríguez de Montesdoca: ${ }^{11}$ Beneficiado de las iglesias de San Julián y de Santa Lucía de Sevilla.

Juan de Villafranca:92 «Cura» de San Salvador, beneficiado de las iglesias de San Martín y Santiago de Niebla.

Íñigo de Agreda: ${ }^{3}$ Canónigo de la Catedral y beneficiado de la iglesia de San Andrés de Sevilla.

Martín de Montiel: ${ }^{94}$ Racionero de la Catedral, beneficiado de San Salvador de Sevilla y cura de la iglesia de Valaguera en la diócesis de Toledo.

El caso más evidente es el de Fernando Álvarez, ${ }^{55}$ con siete rentas procedentes de distintas canonjías, beneficios parroquiales y prestameras, seguido de Juan de Villafranca ${ }^{96}$ y Martín de Montiel, ${ }^{97}$ con tres. En el resto de los casos indicados la acumulación se limita a dos.

\section{LA COMPOSICIÓN DEL CLERO EN CADA PARROQUIA SEGÚN EL BENEFICIO GOZADO ${ }^{98}$}

No puede determinarse el número de beneficiados existentes en las parroquias sevillanas de fines de la Edad Media, porque no disponemos de toda la documentación para cuantificarlos. El número de beneficiados no es equivalente al número de beneficios, pues había clérigos que gozaban de más de uno. Muy poco sabemos de los bienes adscritos a los beneficios. Hemos de conformarnos con la información parcial que nos ofrecen los Protocolos Notariales que, pese a su parcialidad, proporcionan unos datos objetivos.

\footnotetext{
${ }^{88}$ Leg. 19725. Fol. 291 r.

${ }^{89}$ Leg. 2158. Fol. 100r.

${ }^{90}$ Leg. 9101. Fol. 629r.

${ }^{91}$ Leg. 2154. Fol. 487r.

${ }^{92}$ Leg. 2158. Fol. 327v.

${ }^{93}$ Leg. 2157. Fol. 318r.

${ }^{94}$ Leg. 1497. Fol. $21 \mathrm{v}$.

${ }^{95}$ Leg. 3214. Fol. 6v.

${ }^{96}$ Leg. 2158. Fol. 32r.

${ }^{97}$ Leg. 2160. Fol. 281v.

98 Indicamos los clérigos que había en cada parroquia de Sevilla para el período estudiado, dividiéndolos según las distintas categorías y, dentro de éstas, ordenados cronológicamente.
} 


\begin{tabular}{|c|c|c|c|}
\hline Parroquia & «Curas» & Beneficiados & $\begin{array}{l}\text { Bienes adscritos } \\
\text { a los beneficios }\end{array}$ \\
\hline El Salvador & $\begin{array}{l}\text { Pedro Fernández }{ }^{99} \\
\text { Francisco Rodríguez }{ }^{100} \\
\text { Juan de Villafranca }^{101}\end{array}$ & & \\
\hline $\begin{array}{l}\text { Omnium } \\
\text { Sanctorum }\end{array}$ & & Gonzalo Fernández Nieto ${ }^{102}$ & $\begin{array}{l}\text { Unas casas en Santa María } \\
\text { Magdalena }{ }^{103}\end{array}$ \\
\hline San Andrés & $\begin{array}{l}\text { Antón Fernández }{ }^{104} \\
\text { Antón Martínez }{ }^{105} \\
\text { Juan Sánchez de Carmona }{ }^{106} \\
\text { Juan de Carmona } \\
\text { Diego de Lemos }^{108}\end{array}$ & $\begin{array}{l}\text { Diego de Torres }{ }^{109} \\
\text { Alfonso de Cueva }{ }^{110} \\
\text { Íñigo de Agreda }{ }^{111}\end{array}$ & $\begin{array}{l}\text { Unas casas en San Andrés } \\
\text { arrendadas por tres vidas y } \\
\text { un precio de } 1.200 \text { mara- } \\
\text { vedís y cuatro gallinas } 112\end{array}$ \\
\hline San Bartolomé & & $\begin{array}{l}\text { Diego Serrano }{ }^{113} \\
\text { Diego Sánchez Caballo }{ }^{114}\end{array}$ & \\
\hline San Esteban & & Julián Hurtado de Mendozaa ${ }^{115}$ & \\
\hline San Gil & Francisco Marmolejo 116 & & \\
\hline San Ildefonso & & $\begin{array}{l}\text { Pedro Rodríguez de León }{ }^{117} \\
\text { Rodrigo de León }{ }^{118}\end{array}$ & \\
\hline
\end{tabular}

${ }^{99}$ En 1495: Leg. 9099. Fol. 183v.

${ }^{100}$ En 1497:Leg. 1497. Fol. 271r.

${ }^{101}$ En 1500: Leg. 1497. Fol. 73v. Hazañas y La Rua, J. 1909. Maese Rodrigo (1444-1509): 355. Sevilla: Izquierdo y Cía.

102 En 1499: Leg. 19725. Fol. 58r.

${ }^{103}$ Leg. 3211. Fols. 4v., 11v.

${ }^{104}$ En 1466: Leg. 17414. Fol. 3r.

${ }^{105}$ En 1466: Leg. 17414. Fol.46r.

${ }^{106}$ En 1496: Leg. 17422. Fol. 409v.

${ }^{107}$ En 1500: Leg. 2155. Fol. 364r.

${ }^{108}$ En 1502: Leg. 2165. Fol. 468r.

${ }^{109}$ En 1496: Leg. 17422. Fol. 409v.

${ }^{110}$ En 1500: Leg. 2160. Fol. 392r.

${ }^{111}$ En 1500: Leg. 2157. Fol. 318r.; Hazañas y La Rua, J. 1909: 220.

112 Leg. 2161. Fol. 204r.

${ }^{113}$ En 1497: Leg. 1497. Fol. 498v., Hazañas y La Rua, J. 1909: 341.

${ }^{114}$ En 1500: Leg. 17425. Fol. 58r.

115 En 1500: Leg. 2158. Fol. 19v.

116 En 1499: Leg. 17425. Fol. 274r.

${ }_{117}$ En 1480: Leg. 17425. Fol. 58r.

118 En 1500: Leg. 2158. Fol. 217r. 


\begin{tabular}{|c|c|c|c|}
\hline Parroquia & «Curas» & Beneficiados & $\begin{array}{l}\text { Bienes adscritos } \\
\text { a los beneficios }\end{array}$ \\
\hline San Isidoro & & $\begin{array}{l}\text { Luis Clemente }^{119} \\
\text { Diego de Ojeda' } \\
\text { Juan de Cardona } \\
\text { Nicolás de Ortega } \\
{ }^{122}\end{array}$ & $\begin{array}{l}\text { Un mesón en San Isidoro } \\
\text { y unas casas en el Arquillo } \\
\text { de la Alfafa, arrendadas por } \\
2.000 \text { maravedís y un par } \\
\text { de gallinas }^{124}\end{array}$ \\
\hline San Juan & $\begin{array}{l}\text { Juan Sánchez de San Gill } \\
\text { Juan García de San Gil }\end{array}$ & & \\
\hline San Julián & & Juan de Ortega ${ }^{127}$ & \\
\hline San Llorente & $\begin{array}{l}\text { Alfonso Sánchez }{ }^{128} \\
\text { Diego Martínez } \\
\text { Francisco Pérez } \\
\text { Andrés García } 131 \\
\text { Andrés González } \\
\text { Juan de Monnegro }{ }^{133}\end{array}$ & $\begin{array}{l}\text { Cristóbal Caldera }{ }^{134} \\
\text { Calixto Martínez }{ }^{135}\end{array}$ & \\
\hline San Marcos & Diego de Gallegos ${ }^{136}$ & Gonzalo Farfán 137 & \\
\hline San Martín & $\begin{array}{l}\text { Diego de Baena } \\
\text { Diego Fernández Barba }^{139} \\
\text { Francisco de Madrid }^{140} \\
\text { Gonzalo Martínez }^{141}\end{array}$ & Andrés González Poyatos ${ }^{142}$ & $\begin{array}{l}\text { Unas casas en San Martín } \\
\text { arrendadas por tres vidas y } \\
\text { cierto precio } 0^{43}\end{array}$ \\
\hline San Miguel & $\begin{array}{l}\text { Bartolomé Martínez }{ }^{144} \\
\text { Andrés Ferrández } \\
\text { Gonzalo Carrillo }\end{array}$ & Gonzalo Díaz ${ }^{147}$ & \\
\hline
\end{tabular}

\footnotetext{
119 En 1474: Leg. 9098. Fol. 246r.

${ }^{120}$ En 1476: Leg. 9098. Sin foliar.

${ }^{121}$ En 1500: Leg. 2158. Fol. 130r.

122 Ídem.

${ }^{123}$ Leg. 9098. Fol. 147v.

${ }^{124}$ Leg. 9200. Fol. 49v.

125 En 1493: Leg. 17419. Fol. 250v.

${ }^{126}$ En 1501: Leg. 2160. Fol. 278r.

${ }_{127}$ En 1502: Leg. 1500. Fol. 294v.

${ }^{128}$ En 1441: Leg. 210. Fol. 21v.

129 En 1462: Leg. 17413. Fol. 8v.

${ }^{130}$ En 1499: Leg. 17425. Fol. 299r.

${ }^{131}$ En 1500: Leg. 2157. Fol. 543v.

132 En 1502: Leg. 2161. Fol. 70v.

${ }^{133}$ En 1502: Leg. 2161. Fol. 176r.
}

${ }^{134}$ En 1500: Leg. 2158. Fol. 130r.
${ }^{135}$ En 1501: Leg. 1499. Fol. 879r.
${ }^{136}$ En 1496:Leg. 17422. Fol. 27r.
${ }^{137}$ En 1498: Leg. 3211. Fol. 118r.
${ }^{138}$ En 1495: Leg. 2155. Fol. 545r.
${ }^{139}$ En 1495: Leg. 2155. Fol. 554r.
${ }^{140}$ En 1501: Leg. 3217. Fol. 152v.
${ }^{141}$ En 1504: Leg. 2166. Fol. 589r.
${ }^{142}$ En 1502: Leg. 2161. Fol. 280r.
${ }^{143}$ Leg. 2161. Fol. 266v.
${ }^{144}$ En 1488: Leg. 9100 . Fol. 311r.
${ }^{145}$ En 1492: Leg. 17418. Fol. 10v.
${ }^{146}$ En 1496: Leg. 17422. Fol. 30v.
${ }^{147}$ En 1492: Leg. 17418. Fol. 10v. 


\begin{tabular}{|c|c|c|c|}
\hline Parroquia & «Curas» & Beneficiados & $\begin{array}{l}\text { Bienes adscritos } \\
\text { a los beneficios }\end{array}$ \\
\hline San Nicolás & Alfonso González ${ }^{148}$ & Alfonso García de las Cuevas ${ }^{149}$ & $\begin{array}{l}\text { Dos pares de casas en San } \\
\text { Nicolás, cuyas rentas } \\
\text { anuales eran de } 800 \text { mara- } \\
\text { vedís y seis gallinas s } 150 \text {, y } \\
960 \text { maravedís más dos pa- } \\
\text { res de gallinas }{ }^{151}\end{array}$ \\
\hline San Pedro & Juan Tomás ${ }^{152}$ & Nicolás Brazos de Hierro ${ }^{153}$ & \\
\hline San Román & $\begin{array}{l}\text { Juan de Carmona }{ }^{154} \\
\text { Diego Martínez }{ }^{155}\end{array}$ & Martín López ${ }^{156}$ & \\
\hline San Vicente & $\begin{array}{l}\text { Miguel Pérez }^{157} \\
\text { Juan de Soto } \\
\text { Antón Fernández } \\
\text { Fernando Martínez }^{150} \\
\text { Pedro González } \\
\text { Francisco Pisano }^{162} \\
\text { Pedro Díaz } \\
\text { Diego de Oviedo } \\
\text { Dien }^{164}\end{array}$ & Antón de Cueva ${ }^{165}$ & $\begin{array}{l}\text { El Donadío de Torres, } \\
\text { arrendado por con año y } \\
\text { una renta anual de } 50 \text { cahí- } \\
\text { ces de pan terciado y cinco } \\
\text { fanegas de granazón }{ }^{166}\end{array}$ \\
\hline Santiago & Cristóbal Rodríguez ${ }^{167}$ & $\begin{array}{l}\text { Cristóbal Caro }{ }^{168} \\
\text { Martín Sánchez }{ }^{169} \\
\text { Diego González Caballo }^{170}\end{array}$ & \\
\hline Santa Ana & $\begin{array}{l}\text { Bartolomé Fernández Tarste }{ }^{171} \\
\text { Alfonso Pérez }{ }^{172} \\
\text { Pedro García de Segovia }{ }^{173} \\
\text { Alfonso Pérez de las Heras }{ }^{174} \\
\text { Charles Núñez }{ }^{175}\end{array}$ & $\begin{array}{l}\text { Diego Martínez de Cala }{ }^{176} \\
\text { Bartolomé Martín de Mayo }{ }^{177} \\
\text { Alfonso Pérez de las Heras }{ }^{178}\end{array}$ & \\
\hline
\end{tabular}

${ }^{148}$ En 1504: Leg. 9102. Fol. 533v.

149 En 1499: Leg. 2158. Fol. 130r.

150 Leg. 19725. Fol. 260v.

${ }^{151}$ En 1486: Leg. 9100. Fol. 298r.

152 En 1478: Leg. 17416. Fol. 185v.

${ }^{153}$ Leg. 3211. Fol. 11v.

${ }_{154}$ En 1503: Leg. 2163. Fol. 225v.

155 En 1504: Leg. 1501. Fol. 612r.

156 En 1499: Leg. 17425. Fol. 17v.

${ }^{157}$ En 1462: Leg. 17413. Fol. 4v.

${ }^{158}$ En 1466: Leg. 17414. Fol. 26r.

${ }^{159}$ En 1466: Leg. 17414. Fol. 46r.

${ }^{160}$ En 1477: Leg. 17415. Fol. 112r.

${ }^{161}$ En 1492: Leg. 1500. Fol. 298r.

162 En 1500: Leg. 2158. Fol. 80v.

${ }^{163}$ En 1503: Leg. 2161. Fol. 395v.
164 En 1502: Leg. 2164. Fol. 174r.

${ }_{165}$ En 1499: Leg. 3219. Fol . 8r.

${ }^{166}$ Leg. 2156. Fol. 71v.

167 En 1458: Leg. 17414. Fol. 30v.

${ }_{168}$ En 1495: Leg. 2155. Fol. 634r.

${ }^{169}$ En 1500: Leg. 2158. Fol. 130r.

${ }^{170}$ En 1500: Leg. 3219. Fol. 8r.

171 En 1462: Leg. 17413. Fol. 35r.

172 En 1500: Leg. 2157. Fol. 546v.

${ }^{173}$ En 1501: Leg. 1500.Fol. 294v.

174 En 1503: Leg. 2163. Fol. 72r.

175 En 1504: Leg. 2166. Fol. 22r.

176 En 1473: Leg. 3219. Fol. 8r.; Hazañas y

La Rua, J. 1909: 283.

177 En 1502: Leg. 3221. Fol. 117r.

${ }^{178}$ En 1503: Leg. 2163. Fol. 72r. 


\begin{tabular}{|c|c|c|c|}
\hline Parroquia & «Curas» & Beneficiados & $\begin{array}{l}\text { Bienes adscritos } \\
\text { a los beneficios }\end{array}$ \\
\hline Santa Catalina & $\begin{array}{l}\text { Cristóbal Rodríguez }{ }^{179} \\
\text { Alfonso Fernández Farfán }{ }^{180}\end{array}$ & $\begin{array}{l}\text { Pedro Ponce, } \\
\text { clérigo de Córdoba }{ }^{181} \\
\text { Diego Sánchez Negrete } 182 \\
\text { Antón de León } 183\end{array}$ & \\
\hline Santa Cruz & $\begin{array}{l}\text { Cristóbal Martínez }{ }^{184} \\
\text { Juan de la Torre }\end{array}$ & & \\
\hline Santa Lucía & Pedro Méndez 186 & $\begin{array}{l}\text { Cristóbal Martínez }{ }^{187} \\
\text { Juan Bernal }{ }^{188} \\
\text { Juan Martínez }{ }^{189}\end{array}$ & \\
\hline $\begin{array}{l}\text { Santa María } \\
\text { Magdalena }\end{array}$ & $\begin{array}{l}\text { Antonio de Ribera }{ }^{190} \\
\text { Bartolomé Fernández }{ }^{191}\end{array}$ & $\begin{array}{l}\text { Juan García Pacheco }{ }^{192} \\
\text { Fernando Ruiz de Ojeda }{ }^{193} \\
\text { Francisco López }{ }^{194} \\
\text { Antón Rodríguez }{ }^{195} \\
\text { Rodrigo de Montesdoca }{ }^{196}\end{array}$ & \\
\hline Santa Marina & $\begin{array}{l}\text { Juan de Bastida }{ }^{197} \\
\text { Pedro Martínez }\end{array}$ & $\begin{array}{l}\text { Esteban García }{ }^{199} \\
\text { Cristóbal de Ribera }{ }^{200} \\
\text { Pedro Martínez }\end{array}$ & \\
\hline $\begin{array}{l}\text { San Sebastián } \\
\text { (ermita) }\end{array}$ & & Juan Martínez 202 & \\
\hline $\begin{array}{l}\text { Santa María la } \\
\text { Blanca (ermita) }\end{array}$ & Antón López ${ }^{203}$ & & \\
\hline
\end{tabular}

179 En 1498: Leg. 2156. Fol. 388r.

180 En 1499: Leg. 17425. Fol. 90r.

181 En 1498: Leg. 2156. Fol. 388r.

182 En 1499: Leg. 17425. Fol. 90r.

${ }_{183}$ En 1504: Leg. 3213. Fol. 21r.

${ }^{184}$ En 1499: Leg. 1497. Fol. 30r.

185 En 1504: Leg. 3222. Fol. 33v.

186 En 1502: Leg. 1500. Fol. 298r.

187 En 1500: Leg. 2158. Fol. 130r.

188 En 1500: Leg. 3219. Fol. 8r.

${ }^{189}$ En 1502: Leg. 1500. Fol. 294v.

190 En 1492: Leg. 3213. Fol. 13v. Hazañas y

La Rua, J. 1909: 264.
191 En 1497: Leg.1 497. Fol. 207r.

${ }^{192}$ En 1474: Leg. 9098. Fol. 80v.

${ }_{193}$ En 1496: Leg. 2154. Fol. 189r.

${ }^{194}$ En 1499: Leg. 3217. Fol. 152v.

${ }^{195}$ En 1500: Leg. 1501. Fol. 427v.

${ }^{196}$ En 1501: Leg. 1499. Fol. 240r.

${ }^{197}$ En 1495: Leg. 2155. Fol. 100v.

198 En 1498: Leg. 17424. Fol. 192r.

${ }^{199}$ En 1486: Leg. 17416. Fols. 170r., 215r.

${ }^{200}$ En 1499: Leg. 17425. Fol. 58r.

${ }^{201}$ En 1502: Leg. 2161. Fol. 315v.

${ }^{202}$ En 1500: Leg. 1500. Fol. 294v.

${ }^{203}$ En 1501: Leg. 9101. Fol. 104r.

Hispania Sacra, LXIV

130, julio-diciembre 2012, 497-523, ISSN: 0018-215X, doi: 10.3989/hs.2012.015 
En resumen, según la documentación, la parroquia con mayor número de beneficiados «curas» es la de San Vicente, con ocho, seguida de las de San Llorente, con seis, San Andrés, con cinco y Santa Ana, con cinco. Encabeza la lista de los beneficiados simples Santa María Magdalena, con cinco, seguida de San Isidoro, con cuatro y de las parroquias que cuentan con tres: San Andrés, Santiago, Santa Ana, Santa Catalina, Santa Lucía, y Santa Marina.

\section{CONCLUSIONES}

Las escribanías públicas de Sevilla tuvieron entre sus clientes más activos a un número destacado de miembros del clero secular. La documentación a ellos referida es extraordinariamente numerosa, lo que evidencia su importancia y protagonismo indiscutibles en Sevilla al fin de la Edad Media. Su estudio ha permitido conocer el clero de las parroquias y, más concretamente, el universo de los beneficios parroquiales, sus titulares y los negocios de que fueron objeto

Definidos y analizados los conceptos beneficio, beneficiado titular, beneficiado servidero, administrador del beneficio y beneficiado cural, la documentación, a través de varios ejemplos claros, revela cómo los beneficios de Sevilla eran los más ricos de Castilla, dadas sus pingües rentas percibidas y sus cuantiosas propiedades. Eso explica que de un beneficio participaran dos o tres clérigos.

Los Protocolos Notariales confirman lo sostenido en otros estudios: en la diócesis de Sevilla las parroquias estuvieron dotadas de un número de beneficiados mayor o menor, conforme a la cuantía de sus rentas, pero se trataba de simples beneficiados y ninguno de ellos beneficiado cura propio. Aunque estos beneficiados utilizasen el título de curas y popularmente fuesen denominados como tales, sobre ellos no recaía la obligación de la cura de almas.

Como tales simples beneficiados, contrataban a un segundo beneficiado, el servidero, para que desarrollase las funciones propias de sus beneficios.

Los datos ofrecidos por la documentación acotada nos permiten introducir un matiz novedoso en cuanto a los estudios realizados hasta el momento: esta situación presente en la documentación de don Remondo para el siglo XIII, documentamos, con hechos concretos, que perdura en la segunda mitad del siglo $\mathrm{XV}$. La imagen del beneficio es la de una propiedad más dentro del patrimonio clerical, sometida a un contrato de servicios por parte del titular, y que además cuenta con un administrador encargado de gestionar las rentas generadas.

Al igual que en otros lugares Sevilla contó con un instituto eclesiástico, una Universidad, integrado por sus beneficiados. Hemos estudiado su composición y su organigrama gubernativo así como las bases patrimoniales que aseguraban económicamente su existencia. El análisis de los negocios a los que sometieron a éstas revela una práctica mercantil común a la de otros colectivos eclesiásti- 
cos con unas pautas compartidas por todos ellos. En su rol de cliente de las escribanías públicas la Universidad de beneficiados se vio inmersa en cuantos mecanismos articulaban la economía de la ciudad y en las mismas condiciones que cualquier particular.

Finalmente, queremos insistir en la consecuencia que se deriva de esta riqueza económica en las parroquias sevillanas y de la dedicación que la gestión de la misma exigía a los beneficiados: la escasa atención pastoral a los parroquianos y a la cura de sus almas. Situación agravada por el hecho de que un buen número de clérigos titulares de beneficios ni siquiera residían en la ciudad donde la parroquia en la que éstos estaban situados se localizaba. Los parroquianos tendrían la oportunidad de coincidir con el beneficiado en el momento en que fuese a recoger las rentas que le pertenecían, siempre que no lo hiciese un administrador, de tal manera que, en lugar de estar vinculados por lazos de carácter religioso y pastoral, pueblo y clero se unían por vínculos simplemente mercantilistas.

\section{BIBLIOGRAFÍA}

Aldea, Q. 1973. «La economía de las iglesias locales en la Edad Media y Moderna». Hispania Sacra XXVI: 27-42.

Aranda Pérez, F. J. 2000. «El clero parroquial también se acabilda. El cabildo de curas y beneficazos de Toledo», en Sociedad y élites eclesiásticas en la España Moderna: 237-287. Cuenca: Universidad de Castilla-La Mancha.

Barrio Gonzalo, M. 1996. «El clero diocesano: beneficios y beneficiados», en Historia de la diócesis de Valladolid: 123-150. Valladolid: Diputación de Valladolid.

Borrero Fernández, M. 2003. «Efectos del cambio económico en el ámbito rural. Los sistemas de crédito en el campo sevillano (fines del siglo XV y principios del XVI)», en Mundo rural y vida campesina en la Andalucía medieval: 40-41. Granada: Universidad de Granada.

Candau Chacón, M. L. 1998. «Las formas de vida eclesiástica y las fuentes notariales», en En torno a la documentación notarial y a la historia: 111-124. Sevilla: Colegio Notarial.

Cárcel Ortí, M. M. 2005. «El clero secular en Europa en la Baja Edad Media». Anuario de Estudios Medievales 35/2: 971-1050.

Nieto Soria J.M. 2004. «El clero secular». Medievalismo: Boletín de la Sociedad Española de Estudios Medievales, 13-14: 95-112.

Carmona García, J. I. 1993. El extenso mundo de la pobreza: la otra cara de la Sevilla Imperial: 35. Sevilla: Ayuntamiento de Sevilla. 
Collantes de Terán Sánchez, A. 1979. «Génesis de la gran propiedad en la Baja Edad Media. La propiedad eclesiástica sevillana», en La economía agraria en la Historia de España: 133-140. Madrid: Fundación Juan March.

Collantes de Terán Sánchez, A. 1989. «El mercado inmobiliario en Sevilla (Siglos XIII-XV)», en D'une Ville à L'autre: Structures Matérielles et Organisation de L'espace dans les Villes Européennes (XIII-XVI Siècle). Actes du Colloque organisé par l'Ecole française de Rome: 227-242. Roma: 1'Ecole française de Rome.

Collantes de Terán Sánchez, A. 1999. «Moneda y cambios en la Sevilla bajomedieval», en Dinero, moneda y crédito en la monarquía hispánica: actas del Simposio Internacional «Dinero, moneda y crédito: de la monarquía hispánica a la integración monetaria Europea»: 59-82. Madrid: Fundación ICO.

Collantes de Terán Sánchez, A. 2007. «El modelo meridional: Sevilla», en XXXIII Semana de Estudios Medievales de Estella. Mercado inmobiliario y paisajes urbanos en el occidente europeo: siglos XI-XV: 591-630. Pamplona: Gobierno de Navarra.

Fernández Conde, F.J. 1994. La Iglesia de Asturias en la Baja Edad Media. Estructuras económico-administrativas en el tardomedievo. Oviedo: Instituto de Estudios Asturianos.

García y García, A. 1996. «Parroquia, arciprestazgo y arcedianato: origen y desarrollo». Memoria Ecclesiae VIII: 19-40.

González Jiménez, M. 1974. «Archivo de la Universidad de Beneficiados de Carmona. Catálogo de documentación medieval». Historia, Instituciones y documentos 1: 361-387.

González Jiménez, M. 1975. «La Universidad de beneficiados de Carmona. Estudio de la formación de una gran propiedad eclesiástica» en Actas de las I Jornadas de Metodología aplicada a las Ciencias Históricas. Historia Medieval, v. II: 155-159. Santiago de Compostela: Universidad de Santiago.

Igual Luis, D. 2004. «Las perspectivas de investigación sobre fondos notariales en Castilla», en Aragón en la Edad Media: perspectivas actuales sobre las fuentes notariales de la Edad Media: 127-152. Zaragoza: Universidad de Zaragoza.

Jacquart, J. 1973. «Sources Notariales et Historie Rurale», en Actas del II Coloquio de Metodología Histórica Aplicada. La Documentación Notarial y la Historia. 239-254. Santiago de Compostela: Universidad de Santiago.

Ladero Quesada, M.A. 1982. «Moneda y tasa de precios en 1462. Un episodio ignorado en la política económica de Enrique IV de Castilla», en El siglo XV en Castilla. Fuentes de renta y política fiscal: 114-142. Barcelona: Ariel. 
Mackay, A. 2006. Moneda, precios y politica en la Castilla del siglo XV. Granada: Universidad de Granada.

Martín, J. L. 1975. «Diezmos eclesiásticos: notas sobre la economía de la sede zamorana (siglos XII-XIII), en Actas de las I Jornadas de Metodología Aplicada de las Ciencias Históricas, Vol. 2: 69-78. Madrid: Fundación Universitaria Española.

Martín, J. L. 2005. «Beneficios y oficios del clero rural castellano (siglos XIII-XV)». Anuario de Estudios Medievales 35, 2: 693.

Miguélez Domínguez, L., Alonso Morán, S., Cabreros de Anta, M. 1954. Código de Derecho canónico: 47. Madrid: Editorial Católica.

Mollat, G. 1921. La collation des bénéfices eclésiastiques sous les papes d'Avignon. París: Fontemoing \& cie.

Osorio Muñoz, M. 1984. «El bajo clero en Jaén en el tránsito a la Edad Moderna. La Universidad de Curas Párrocos», en Actas del III Coloquio de Historia Medieval Andaluza: grupos no privilegiados: 457-471. Jaén: Diputación Provincial de Jaén.

Ostos Salcedo, P. y Pardo Rodríguez, M. L. 1995. El notariado andaluz en el tránsito de la Edad Media a la Edad Moderna. Sevilla: Colegio Notarial.

Parejo Delgado, M. J. 1982. «Los estatutos de la Universidad de clérigos beneficiados de Arjona (1488). Textos y comentarios», en Actas del I Coloquio de Historia de Andalucía. Andalucía Medieval: 369-382. Córdoba: Diputación Provincial de Córdoba.

Pérez González, S.M. 2005. Los laicos en la Sevilla bajomedieval. Sus devociones y cofradías: 89-102. Huelva: Universidad de Huelva.

De Reina, V. 1965. El sistema beneficial. Pamplona: Universidad de Navarra.

Rodríguez Molina, J. 1986. El Obispado de Baeza-Jaén. Organización y economía diocesanas (siglos XIII-XVI). Jaén: Diputación Provincial de Jaén.

Sánchez Gordillo, A. 2002. Memorial Sumario de los Arzobispos de Sevilla y otras obras: 176-178. Sevilla: Ayuntamiento de Sevilla.

Sánchez Herrero, J. 1976. Concilios provinciales y sínodos toledanos de los siglos XIV y XV. La religiosidad cristiana del clero y pueblo: 177. La Laguna: Universidad de La Laguna

Sánchez Herrero, J. 1978. Las diócesis del Reino de León. Siglos XIV y XV: 143-191. León: Centro de investigación y estudios «San Isidoro».

Sánchez Herrero, J. 1992. «La diócesis de Sevilla entre finales del siglo XVI y comienzos del XVII. Las visitas ad limina de los arzobispos de Sevilla D. Rodrigo de Castro, 1597, y D. Fernando Niño de Guevara, 1602 y 1605». Isidorianum 1: 233-261. 
Sánchez Herrero, J. 1994. «La vida eclesiástica y la religiosidad cristiana en Écija en el paso del siglo XVI al XVII», en Luis Vélez de Guevara y su época. IV Congreso de Historia de Écija: 179-205. Sevilla: Fundación el Monte.

Sánchez Herrero, J. 1997. «El Trabajo del clero en la Edad Media». Acta historica et archeologica medieavalia, 18: 93.

Sánchez Herrero, J. 1998. «La Iglesia y la religiosidad en la Huelva Medieval», en Huelva en la Edad Media. Reflexiones aportaciones y nuevas perspectivas veinte años después: 155 . Huelva: Universidad de Huelva.

Sánchez Herrero, J. 2002. «El clero en tiempos de Isabel I de Castilla», en J. Valdeón Varuque. II Simposio sobre el Reinado de Isabel la Católica: Sociedad y economía en tiempos de Isabel La Católica:151-182. Valladolid: Ámbito

Sánchez Herrero, J. 2003. «El clero, la organización eclesiástica y la religiosidad cristiana en Carmona durante los siglos XVI al XVIII», en Carmona en la Edad Moderna: 427-462. Carmona: Ayuntamiento de Carmona.

Sánchez Herrero, J. 2008. Historia de la Iglesia en España e Iberoamérica: desde sus incicios hasta el siglo XX: 147. Madrid: Sílex.

Sanz Sancho, I. 2006. La Iglesia de Córdoba (1236-1454). Una diócesis de la provincia eclesiástica de Toledo en la Baja Edad Media: 271. Madrid: Fundación Ramón Areces.

Sempere y Guarinos, J. 1822. Historia de las rentas eclesiásticas de España. Madrid: Imprenta de I. Sancha.

Tejada y Ramiro, J. 1849. Colección de cánones y de todos los concilios de la Iglesia de España y América, tomo III: 486-488. Madrid: Imprenta de D. Pedro Montero.

Torres Gutiérrez, A. 2000. Iglesia y fisco en la Historia de España. Madrid: Universidad Complutense. 